\title{
MATERNAL AND FOETAL OUTCOME IN ABRUPTIO PLACENTAE
}

\author{
Sonal Phadtare1, Sanjay Kumar Patil ${ }^{2}$ \\ ${ }^{1}$ Resident, Department of Obstetrics and Gynaecology, Krishna Institute of Medical Sciences, Karad. \\ ${ }^{2}$ Professor, Department of Obstetrics and Gynaecology, Krishna Institute of Medical Sciences, Karad.
}

\section{ABSTRACT}

\section{BACKGROUND}

An Abruptio Placentae (AP) is one of the most serious obstetric complication and life-threatening for both the foetus and mother worldwide. The situation is worse in resource-poor settings including India; it contributes to significant maternal and perinatal morbidity and mortality.

\section{MATERIALS AND METHODS}

This was a retrospective, observational, hospital-based study conducted from May 2014 to June 2016. All patients with clinical diagnosis of Abruptio Placentae over 28 wks of gestation presenting to Department of Obstetrics and Gynaecology were included in the study.

\section{RESULTS}

Out of 100 cases studied, $54 \%$ cases were multiparous. Most common gestational age was 28 - 32 wks, that is $37 \%$. Most of the patients presented with Haemoglobin levels between 6 - 8 gm\% (moderate anaemia), i.e. 56\%. Maximum cases with Abruptio placentae underwent C-section, i.e. 76\%; $86 \%$ of patients needed blood transfusion and 95\% patients were anaemic. Other major maternal complications were PPH and renal failure. One maternal death occurred due to Abruptio Placentae complicated with DIC; $47 \%$ of babies needed NICU admission. Only 6 babies were shifted to mother's side after delivery. Early neonatal death due to birth asphyxia and prematurity was $5 \%$. Intrauterine deaths which were diagnosed on ultrasonography on admission were $40 \%$. Perinatal deaths which occurred during course of labour, i.e. fresh still birth were $2 \%$. Overall mortality was $47 \%$.

\section{CONCLUSION}

In our study, maternal mortality was very less due to easy availability of blood and blood products and immediate resuscitation. Perinatal mortality was high to late presentation of the patient to the hospital. Caesarean section rate was high in our setup, but this was for better maternal and perinatal outcome. The predictors of maternal adverse outcomes were found to be DIC, anaemia, PPH, ICU admission, number of blood transfusion, while predictors for perinatal death were low birth weight, prematurity, birth asphyxia, low Apgar score and retroplacental clot. Despite advances in medical technology, the diagnosis of abruption is still a clinical one and early recognition and prompt delivery is the key for better outcome.

\section{KEYWORDS}

Abruption, Foetomaternal Outcome, Predictors.

HOW TO CITE THIS ARTICLE: Phadtare S, Patil SK. Maternal and foetal outcome in abruptio placentae. J. Evolution Med. Dent. Sci. 2017;6(22):1745-1749, DOI: 10.14260/Jemds/2017/384

\begin{tabular}{|c|c|}
\hline $\begin{array}{l}\text { BACKGROUND } \\
\text { Abruptio placentae (AP) refers to bleeding at the decidual- } \\
\text { placental interface, which causes placental detachment over } \\
28 \text { weeks of gestation and prior to delivery of foetus. }{ }^{1} \\
\text { Abruptio placentae are known by several names such as } \\
\text { accidental haemorrhage, ablation placenta and premature } \\
\text { separation of placenta. "Riding asunder of placentae" is Latin } \\
\text { meaning of Abruptio placentae. }{ }^{1} \text { Due to placental detachment, } \\
\text { foetus is deprived of nutrition and oxygen leading to } \\
\text { perinatal mortality and morbidity. }{ }^{2} \text { Although, aetiology of }\end{array}$ & $\begin{array}{l}\text { vertex presentation, polyhydramnios, IUGR, advanced } \\
\text { maternal age, maternal trauma, cigarette smoking, alcohol } \\
\text { consumption, PROM, retroplacental fibromyoma are } \\
\text { associated with Abruptio placentae. }{ }^{2,3,4,5,6,7,8,9} \text { This premature } \\
\text { detachment commonly produces pain and vaginal bleeding. } \\
\text { The main common presentation includes vaginal bleeding, } \\
\text { uterine tenderness, abdominal pain, abnormal uterine } \\
\text { contractions, foetal distress, foetal death, premature labour, } \\
\text { maternal haemodynamic instability.3,6 There are three types } \\
\text { of Abruptio placentae. }\end{array}$ \\
\hline
\end{tabular}
Abruptio placentae is not fully understood it is generally multifactorial, that is impaired placentation, uteroplacental underperfusion, hypertensive disorder in pregnancy, non-

Financial or Other, Competing Interest: None.

Submission 01-02-2017, Peer Review 02-03-2017,

Acceptance 09-03-2017, Published 16-03-2017.

Corresponding Author:

Dr. Sonal Phadtare,

1HR, Hospital, Room No. 6,

Krishna Institute of Medical Sciences,

Karad.

E-mail: dr.sonalphadtare@gmail.com

DOI: $10.14260 /$ jemds $/ 2017 / 384$

\section{Revealed Abruption}

Blood tracks between the membranes and escapes through the vagina and cervix.

\section{Concealed Abruption}

Blood collects behind the placentae with no evidence of vaginal bleeding.

\section{Mixed Abruption}

Revealed and concealed both types of abruption are seen.

Maternal complications include haemorrhagic shock, DIC, renal failure, ischaemic necrosis of distal organs, couvelaire uterus leading to PPH.9,10,11 Foetal complications include 
hypoxia, anaemia, growth restriction, prematurity, neurodevelopmental problems and foetal death.9,10 Depending upon the severity of signs and symptoms, Abruptio placentae is divided into:

\section{(Sher's Classification) Grade I}

Mild- This is not recognised clinically before delivery and usually diagnosed by presence of retroplacental clots.

Grade II: Intermediate- The classical signs of Abruptio placentae are present, but foetus is still alive. Patient is haemodynamically stable.

Grade III: Severe- Foetus is dead and coagulopathy may be present.

\section{MATERIALS AND METHODS}

The study was carried out at Department of Obstetrics and Gynaecology, Krishna Institute of Medical Sciences, Karad. The study was carried out from May 2014 to June 2016. The study population included 100 cases presenting with antepartum haemorrhage to Department of Obstetrics and Gynaecology during study period. All patients with clinical diagnosis of Abruptio placentae over 28 wks gestation characterised by painful vaginal bleeding, hypertonic or tense uterus, with or without non-reassuring foetal heart rate/foetal distress, foetal demise, pallor, hypotension were included in study. Presence of retroplacental clots after the delivery supported the diagnosis.

Detailed history was taken on admission and physical examination was done. Obstetric USG was done in cases to rule out other causes of antepartum haemorrhage. Parity, clinical presentation of women, condition of foetus on admission was noted and according to that patients were managed. Retroplacental clots were measured in a kidney dish (corresponding to $500 \mathrm{~mL}$ of blood). Apgar score, weight of baby and gender were noted. According to condition of baby at birth, it was shifted to NICU or mother's side. Patients were monitored for next $24 \mathrm{hrs}$. after delivery and if any complication occurred were noted.

\section{RESULTS}

\section{Baseline Characteristic of Study Participants}

The incidence of abruption increases with maternal age. Out of 100 cases of abruptio placentae admitted in our setup, $62 \%$ cases were from age group between $26-35$ yrs. There were $34 \%$ cases from age group $<25$ yrs., while only $4 \%$ cases were noted in age group $>36$ yrs.

There were conflicting data regarding women of greater parity. Out of 100 cases studied in our Institute, $43 \%$ cases were primiparous; $54 \%$ cases were multiparous, while only $3 \%$ were Grand multiparous.

Most common gestational age for occurrence for Abruptio placentae was 28 - 32 wks of gestation, that is $37 \%$. While $32 \%$ cases of Abruptio placentae were seen at $37 \mathrm{wks}$ and above. There was very less difference noted in occurrence of Abruptio placentae at gestational age between 33 - 36 wks and $>37$ wks. There was difference of only $1 \%$ noted.

Out of 100 cases studied of Abruptio placentae, most of the patients presented with $\mathrm{Hb}$. Levels between $6-8 \mathrm{gm} \%$ (moderate anaemia), i.e. 56\%. While only $7 \%$ cases presented with mild anaemia with $\mathrm{Hb}$. Levels 9 - 11 gm\%. Severe anaemic cases were $37 \%$.

Maximum cases with Abruptio placentae underwent Csection, i.e. $76 \%$. Vaginal delivery was $14 \%$; $9 \%$ of cases needed instrumental delivery. Only one maternal death occurred without being delivered.

\begin{tabular}{|c|c|c|}
\hline Characteristics & $\begin{array}{l}\text { No. of Cases } \\
\text { (Total 100) }\end{array}$ & Percentage \\
\hline \multicolumn{3}{|l|}{ Maternal Age } \\
\hline$<25$ yrs. & 34 & $34 \%$ \\
\hline $26-35$ yrs. & 62 & $62 \%$ \\
\hline$>36$ yrs. & 4 & $4 \%$ \\
\hline \multicolumn{3}{|l|}{ Parity } \\
\hline Primipara & 43 & $43 \%$ \\
\hline Multipara (2 - 3) & 54 & $54 \%$ \\
\hline Grand multipara ( $>3$ ) & 3 & $3 \%$ \\
\hline \multicolumn{3}{|l|}{ Gestational Age } \\
\hline $28-32$ wks & 37 & $37 \%$ \\
\hline $33-36$ wks & 31 & $31 \%$ \\
\hline$>37$ wks & 32 & $32 \%$ \\
\hline \multicolumn{3}{|l|}{ Hb. Levels } \\
\hline $9-11 \mathrm{gm} \%$ & 7 & $7 \%$ \\
\hline $6-8 \mathrm{gm} \%$ & 56 & $56 \%$ \\
\hline$<5$ gm $\%$ & 37 & $37 \%$ \\
\hline \multicolumn{3}{|l|}{ Mode of Delivery } \\
\hline Vaginal Delivery & 14 & $14 \%$ \\
\hline Instrumental Delivery & 9 & $9 \%$ \\
\hline C-section & 76 & $76 \%$ \\
\hline
\end{tabular}

\section{Maternal Adverse Outcome}

$86 \%$ of patients needed blood transfusion and $95 \%$ patients were anaemic, $25 \%$ patients had $\mathrm{PPH}$ and $2 \%$ of them underwent hysterectomy; 30\% patients landed up in DIC; $2 \%$ patients needed dialysis for Acute Renal Failure. One maternal death occurred due to Abruptio placentae complicated with DIC.

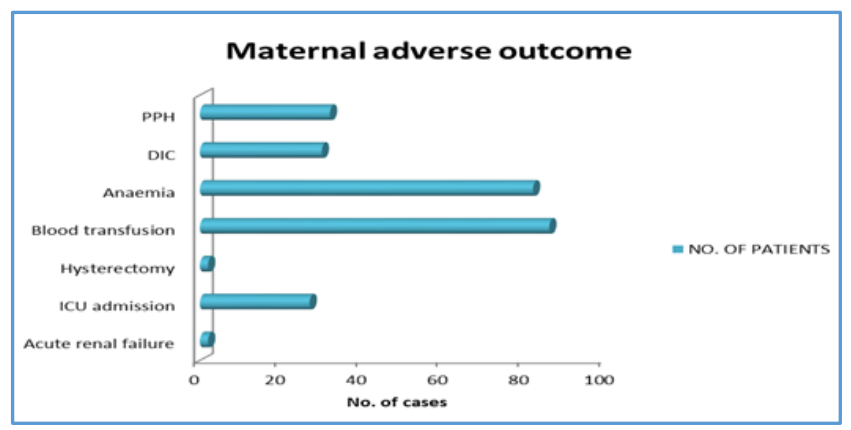

Graph 1

\section{Foetal Adverse Outcomes}

Our study shows that out of 100 cases of Abruptio placentae who delivered in Krishna Hospital, $47 \%$ of babies needed NICU admission. Only 6 babies were shifted to mother's side after delivery. Out of $47 \%$ NICU admissions $29 \%$ babies were shifted to NICU for low Apgar score, while $18 \%$ were shifted to NICU for low birth weight. Early neonatal death due to birth asphyxia and prematurity was $5 \%$. Intrauterine deaths, which were diagnosed on ultrasonography on admission were $40 \%$. Perinatal deaths, which occurred during course of labour i.e. fresh still birth were $2 \%$. 


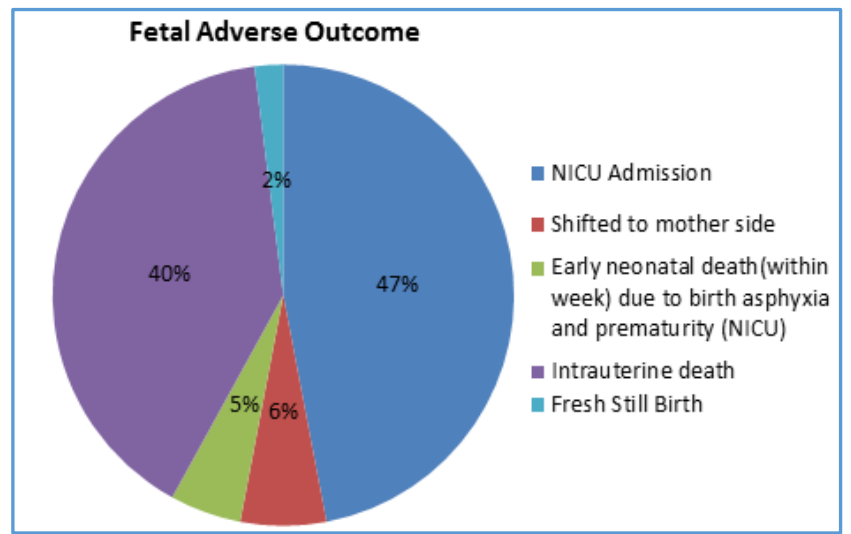

Graph 2

\section{Predictors of Perinatal Outcome}

Out of 100 cases studied, infants born to mother of Abruptio placentae $41 \%$ had very low birth weight, that is < $1.5 \mathrm{kgs}$; $30 \%$ neonates had birth weight $>2.5 \mathrm{kgs}$ and neonates with birth weight between $1.5-2.5 \mathrm{kgs}$ were $29 \%$. Prematurity was one of the important factors that affected perinatal outcome; $37 \%$ cases were born to mother of Abruptio placentae were between gestational age of 28 - 32 wks; $32 \%$ were born at full term, that is > 37 wks of gestation; $31 \%$ cases were between gestational age of $33-36$ wks. Out of total live births, $29 \%$ of neonates had Apgar score below 7 at 5 mins who needed NICU admission; 35\% neonates had low Apgar score at 1 min. Out of 100 mothers with Abruptio placentae, $41 \%$ cases had retroplacental clot between 300 $700 \mathrm{~mL}, 36 \%$ cases had retroplacental clot of size $>700 \mathrm{~mL}$, while $22 \%$ cases had clot size $<300 \mathrm{~mL}$. In only one case of abruptio placentae, the size of clot was not known as the patient died before delivery.

\begin{tabular}{|c|c|c|}
\hline Predictors & $\begin{array}{c}\text { No. of Cases } \\
(100)\end{array}$ & Percentage \\
\hline \multicolumn{3}{|l|}{ Birth Weight } \\
\hline$<1.5 \mathrm{kgs}$ & 41 & $41 \%$ \\
\hline $1.5-2.5 \mathrm{kgs}$ & 29 & $29 \%$ \\
\hline$>2.5 \mathrm{kgs}$ & 30 & $30 \%$ \\
\hline \multicolumn{3}{|l|}{ Gestational Age } \\
\hline $28-32$ & 37 & $37 \%$ \\
\hline $33-36$ & 31 & $31 \%$ \\
\hline$>37$ & 32 & $32 \%$ \\
\hline \multicolumn{3}{|c|}{ Apgar Score (Below 7) } \\
\hline At 1 Min & 35 & $35 \%$ \\
\hline At 5 Mins & 29 & $29 \%$ \\
\hline \multicolumn{3}{|c|}{ Retroplacental Clots } \\
\hline$<300 \mathrm{~mL}$ & 22 & $22 \%$ \\
\hline $300-700 \mathrm{~mL}$ & 41 & $41 \%$ \\
\hline$>700 \mathrm{~mL}$ & 36 & $36 \%$ \\
\hline
\end{tabular}

\begin{tabular}{|c|c|c|}
\hline Predictors & $\begin{array}{c}\text { No. of Cases } \\
(\mathbf{1 0 0})\end{array}$ & Percentage \\
\hline DIC & & \\
\hline Yes & 30 & $30 \%$ \\
\hline No & 70 & $70 \%$ \\
\hline Haemoglobin Levels & & \\
\hline $9-11$ gm $\%$ & 7 & $7 \%$ \\
\hline $6-8$ gm $\%$ & 56 & $56 \%$ \\
\hline$<5$ gm $\%$ & 37 & $37 \%$ \\
\hline No. of Blood Transfusions & & \\
\hline
\end{tabular}

\begin{tabular}{|c|c|c|}
\hline None & 16 & $16 \%$ \\
\hline $1-3$ & 50 & $50 \%$ \\
\hline$>3$ & 34 & $34 \%$ \\
\hline \multicolumn{3}{|c|}{ Fresh Frozen Plasma } \\
\hline None & 20 & $20 \%$ \\
\hline $1-3$ & 49 & $49 \%$ \\
\hline$>3$ & 31 & $31 \%$ \\
\hline \multicolumn{3}{|c|}{ Acute Renal Failure } \\
\hline Yes & 2 & $2 \%$ \\
\hline No & 98 & $98 \%$ \\
\hline \multicolumn{3}{|c|}{ ICU Admission } \\
\hline Yes & 27 & $27 \%$ \\
\hline No & 43 & $43 \%$ \\
\hline \multicolumn{3}{|c|}{ Postpartum Haemorrhage } \\
\hline Yes & 32 & $32 \%$ \\
\hline No & 68 & $68 \%$ \\
\hline
\end{tabular}

Out of 100 cases of Abruptio placentae, 30\% women went into DIC. Haemoglobin levels between 6 - $8 \mathrm{gm} \%$ was noted in $56 \%$ cases. Mild anaemia was seen in $7 \%$ of cases, while patients who had severe anaemia were $37 \%$. Abruptio placentae causes large amount of blood loss in very few time. Patients who got admitted to our Department with Abruptio placentae needed large amount of blood transfusions; $50 \%$ of cases needed 1 - 3 pints of blood transfusion during the hospital stay; $34 \%$ patients needed blood transfusions more than 3 pints. But $16 \%$ of patients did not need any blood transfusion. Fresh Frozen Plasma was other important blood component that was being transfused to patients with Abruptio placentae; $49 \%$ cases needed 1 - 3 number of FFP transfusions; $31 \%$ cases needed transfusion more than 3 pints. No transfusion was needed in $20 \%$ cases. Acute Renal Failure was seen in only $2 \%$ cases in whom dialysis was needed; 98\% cases did not need dialysis; 20 cases with Abruptio placentae had decreased renal output postoperatively. These cases were managed with increase in fluid input to the patient and some patients were given Inj. Lasix IV. Cases of Abruptio placentae might need ICU care postoperatively due to various complications like acute renal failure, severe anaemia, DIC, postpartum haemorrhage, etc. In our study, $27 \%$ cases needed ICU admission for same reasons as above; $43 \%$ cases were shifted directly to the ward but postoperative monitoring of vitals, per vaginal bleeding and urine output was maintained. Cases those were complicated with postpartum haemorrhage were $32 \%$; $68 \%$ cases had no such complication.

\section{DISCUSSION}

Abruptio placentae remain a major cause of perinatal mortality and morbidity globally. It is a most serious concern in the developing world.

The incidence of Abruptio placentae in KIMS was 1.2\%. This incidence is comparable with other studies done in America, Europe and East Asian countries where the incidence of Abruptio placentae is $0.5 \%-1 \% .2,5,12,13$ The incidence of Abruptio placentae in a study done by Soma Mukherjee and Colleagues was $4.4 \%$, which is much higher as compared to our study. A study done by Goodwin and Colleagues showed incidence rate of Abruptio placentae $0.34 \%$, which is comparable with our study. Studies in developing countries showed incidence rate between $2 \%$ $6 \% .14,15$ 
The difference in incidence could partly be explained by the differences in the studied population, study design and diagnostic criteria.

The incidence of abruption increases with maternal age. In our study, incidence of abruption was most common between age group 26 - 35 yrs., which was $62 \%$. This is in contrast to the traditional association with advanced maternal age. One study showed similar incidence as ours with majority of patients between age group 25 - 30 yrs. Placental abruption is prevalent in younger obstetric population in contrast to advanced age, due to marriage at younger age.

In our study, the occurrence of abruptio placentae is higher in multiparous women which is 54\%. This result correlates with many previous studies, but was in contrast to one study done by Sanchez and Colleagues who observed that neither of these factors were associated with Abruptio placentae.

Our study shows incidence rate of Abruptio placentae is more between gestational age of $28-32 \mathrm{wks}$. This result is in contrast with many other studies where an Abruptio placentae was mostly documented in term pregnancies. 15

$93 \%$ cases of cases studied had anaemia and among them $35 \%$ cases had severe anaemia. Similar findings were found in studies from developing countries. ${ }^{15}$ Although same have been reported by many other studies, we cannot conclude that anaemia is direct adverse outcome of Abruptio placentae, as many patients are unbooked with no antenatal record. Also, abruptio placentae cause acute haemorrhage, hence result of haemoglobin levels does not reflect the severity of anaemia. Soma Mukherjee and Colleagues had $96.2 \%$ rate of anaemia in their study. The high frequency of maternal anaemia might have also been contributed by chronic maternal nutritional deficit.

Caesarean delivery in our study was commonest, that is $76 \%$ which is in contrast with many other studies. Shrivastava et al showed only $18 \%$ cases needed caesarean section. ${ }^{9}$ Musarrat Jabeen et al in his study showed incidence of caesarean section as low as $7.94 \%$. The reason for this was that most of the babies were already dead and in many cases patients were in advance labour. The higher rate of caesarean section in our setup was due to late presentation of the patient into the hospital with compromised foetal maternal status, hence needed urgent delivery.

Maternal adverse outcome which was found in our study includes maternal mortality (1\%), need for blood transfusion (86\%), anaemia (93\%), DIC (30\%), PPH (32\%), ICU admission $(27 \%), 2 \%$ patients suffered from acute renal failure while $2 \%$ patients needed obstetric hysterectomy due to primary haemorrhage. Hysterectomy was performed in only $2 \%$ of cases. This result was similar to a study done by Iram et al, who reported incidence of $1.9 \%$. Study conducted in Bugando also showed similar rate of hysterectomy as ours, ICU admission was necessary in $27 \%$ cases. A study reported rate of $13 \%$. Other studies have shown presence of low rate of ICU admission that is between $1 \%$ and $4.5 \% .^{15}$ Late presentation to the hospital with several other complications and presence of comorbidities like PIH, diabetes necessitated close monitoring in ICU. ICU admission was found significant in reducing maternal death, while same findings were observed in many studies. Maternal mortality rate was only $1 \%$ in our study, which is low as compared to other studies from developing countries which had mortality ranging from 3 - 15\%.14,15 Mortality in our study was less due to prompt availability of blood and blood products for immediate resuscitation. DIC was found in $30 \%$ of mothers who had abruption. This finding was higher compared to other studies, where rate was ranging from $4.16 \%$ to $16.5 \%$. Maternal mortality due to DIC was in only $1 \%$ case in our study, which shows close correlation with a study of Godwin S. Macheku et al, which was $1.1 \%$. In a study done by Seema et al, $4.7 \%$ mortality was seen which was much higher as compared to other studies. ${ }^{3}$ Blood transfusion was needed in $84 \%$ cases depending on blood loss and whether patient had DIC or anaemia. Women who required blood transfusions more than 3 units were $34 \%$. Various studies showed blood transfusions required was $50 \%$ to $62 \%$.

In study cases, which needed blood transfusions more than 3 units were 91.4\%. Our study did not find any association between a need for blood transfusion and maternal death possibly, because the direct cause of maternal death was DIC and not anaemia. The rate of postpartum haemorrhage in Abruptio placentae cases has been reported $3 \%$ to $22.2 \%$ in a study conducted by Seema et al. The rate of postpartum haemorrhage was $32 \%$ in our Institute. A study conducted outside had similar rate, that is $36.8 \%$. Such a high incidence has been contributed by cases with severe anaemia and coagulopathy. Sarwar et al reported $22.2 \%$ cases of postpartum haemorrhage, which was a result of atonic uterus, coagulation failure and severe anaemia.

Foetal adverse outcome in Abruptio placentae observed during study period were perinatal mortality (47\%), low birth weight (18\%) and birth asphyxia (29\%). In our study, $40 \%$ foetal deaths occurred in utero; $2 \%$ were still born that died during course of labour; $5 \%$ cases had early neonatal death due to prematurity and birth asphyxia. The higher perinatal mortality rate was comparable with studies like Kramer MS et al, Amornrath Pitaphrom et al.12,15 However, it was contradictory to that reported by WHO 2009 which is $15 \%$, other developed countries reported $9 \%$ to $12 \%$ rate. $1,3,7$ In our study, NICU admission had 5\% perinatal death due to Abruptio placentae.

This rate is very low as compared to other studies. The main reason for this is a good care in NICU. In our study, women with pregnancy complicated with abruptio placentae had more risk of delivering low birth weight baby as compared to women with normal pregnancy. Similar findings were reported in other studies. The high risk of low birth weight delivery among women with Abruptio placentae may be explained by the effect of preterm birth due to premature termination of pregnancy performed by clinician due to severity of Abruptio placentae. In a study, prevalence of abruption in mothers with a female child was low (29.5\%) as compared to mother with a male child (69.5\%). But therein difference in foetal survival observed among the offspring of the mother affected by Abruptio placentae. Gender difference associated with Abruptio placentae has been reported by previous investigators. Perinatal mortality has been strongly associated with Abruptio placentae across the world. In our study, the association was much stronger to low birth weight, 
low Apgar score, severe maternal anaemia, preterm gestation and high volume of retroplacental clot. Similar findings were shown in a study done by Anand et al.

\section{CONCLUSION}

Abruptio placentae are associated with high rate of maternal and foetal morbidity and mortality. Because of this association, the condition predisposing it should be carefully evaluated in order to reduce the occurrence of placental abruption. Unfortunately, neither accurate prediction nor prevention of abruption is possible at the present time. In our study, maternal mortality was very less due to easy availability of blood and blood products and immediate resuscitation. Perinatal mortality was high to late presentation of the patient to the hospital. Caesarean section rate was high in our setup, but this was for better maternal and perinatal outcome. The predictors of maternal adverse outcomes due to Abruptio placentae were found to be DIC, anaemia, PPH, ICU admission, number of blood transfusion and while predictors for perinatal death due to Abruptio placentae was found to be low birth weight, prematurity, birth asphyxia, low Apgar score, retroplacental clot volume between 300 and $700 \mathrm{~mL}$ and caesarean mode of delivery. Despite advances in medical technology, the diagnosis of abruption is still a clinical one. When abruption does occur, there are some strategies that may help minimise the risk of morbidity and mortality associated with this condition. This includes early recognition and prompt delivery in cases in which the foetus is mature.

Improved attendance to antenatal care and timely management of these factors may reduce the risk of Abruptio placentae and associated adverse foetomaternal outcomes. Furthermore, better equipped obstetric and neonatal units will improve both maternal and perinatal outcomes.

Services of healthcare providers can be taken to identify women at risk, early detection and timely referral of these patients for optimal medical management.

\section{ACKNOWLEDGEMENT}

I thank the Department of Obstetrics and Gynaecology of Krishna Institute of Medical Sciences, Karad for allowing me to conduct this study.

Special thanks to Dr. Sanjaykumar Patil for helping me complete the writing of this study as well as the challenging research that lies behind it. He has been a friend and mentor; and without his encouragement and constant guidance I could not have finished this study.

Thanks to Dr. R. P. Patange, Professor and Head of the Department, OBGY, KIMS, Karad and Dr N. S. Kshirsagar, Professor, Department of OBGY, KIMS, Karad for their encouragement and support.

I would also like to thank the rest of the team working in the Department of Obstetrics and Gynaecology; including residents and nurses who supported me in my study. I thank them for all their help and support.

\section{REFERENCES}

[1] Oyelese Y, Ananth CV. Placental abruption. Obstet Gynecol 2006;108(4):1005-16.

[2] Pariente G, Wiznitzer A, Sergienko R, et al. Placental abruption: critical analysis of risk factors and perinatal outcomes. J Matern Fetal Neonatal Med 2011;24(5):698-702.

[3] Bibi S, Ghaffar S, Pir MA, et al. Risk factors and clinical outcome of placental abruption: a retrospective analysis. J Pak Med Assoc 2009;59(10):672-4.

[4] Ananth CV, Savitz DA, Williams MA. Placental abruption and its association with hypertension and prolonged rupture of membranes: a methodologic review and meta-analysis. Obstet Gynecol 1996;88(2):309-18.

[5] Ananth CV, Oyelese Y, Yeo L, et al. Placental abruption in the United States, 1979 through 2001: temporal trends and potential determinants. Am J Obstet Gynecol 2005;192(1):191-8.

[6] Tikkanen M. Etiology, clinical manifestations and prediction of placental abruption. Acta Obstet Gynecol Scand 2010;89(6):732-40.

[7] Ananth CV, Oyelese Y, Prasad V, et al. Evidence of placental abruption as a chronic process: associations with vaginal bleeding early in pregnancy and placental lesions. Eur J Obstet Gynecol Reprod Biol 2006;128(1-2):15-21.

[8] Kumar N, Shekhar C, Kumar P, et al. Kuppuswamy's socioeconomic status scale-updating for 2007. Indian J Paediatr 2007;74(12):1131-2.

[9] Gaufberg SV. Abruptio placentae. 2001.http://www.emedicine.com/emerg/topic12.hm.

[10] Obstetrical Haemorrhage Chap. 32 In: Cunningham FG, MacDonald PC, Gant NF, et al. eds. Williams Obstetrics. 20 $0^{\text {th }}$ edn. USA: Appleton \& Lange 1997:746-55.

[11] Ananth CV, Savitz DA, Williams MA. Placental abruption and its association with hypertension and prolonged rupture of membranes: a methodologic review and meta-analysis. Obstet Gynecol 1996;88(2):309-18.

[12] Kramer MS, Usher RH, Pollack R, et al. Etiologic determinants of abruptio placentae. Obstet Gynecol 1997;89(2):221-6.

[13] Hung TH, Hsieh CC, Hsu JJ, et al. Risk factors for placental abruption in an Asian population. Reprod Sci 2007;14(1):59-65.

[14] Wandabwa J, Doyle P, Kindo P, et al. Risk factors for severe abruptio placenta in Mulago hospital, Kampala, Uganda. Afr Health Sci 2005;5(4):285-90.

[15] Sindh M. Frequency, maternal and fetal outcome of abruptio placenta in rural Parkistan. Pakistan Journal of Medical Science 2010;26:663-6. 